\title{
The resilient physician: Sustaining the healing partnership
}

\author{
“Any idiot can face a crisis—it's this day-to-day living that wears you out." Anton Chekhov
}

\section{Stephen Muse*}

Pastoral Institute, Inc., 2022 15th Ave., Columbus, 31901, Georgia

\section{Introduction}

The original intent of the Hippocratic oath and the desire of both physician and patient for a genuinely humane healing partnership has been under siege for some time now. Since Henry Ford introduced the mass assembly line, business has sought increasing efficiency in production. The advent of computers and health care management as a business has reconfigured physicians to more and more cumbersome record-keeping 'providers' who in some cases are under pressure to see a new patient every 8-12 minutes and patients have morphed into passive 'consumers' who are allowed one problem per visit and conversation must be kept to a minimum.

A 2018 survey of 15,000 doctors in the United States, reported that $42 \%$ of physicians feel burned out, with the highest rates being in the specialties of critical care (48\%), neurology (48\%) and family medicine (47\%). ${ }^{1}$ This is twice the rate existing among professionals in other fields ${ }^{2}$. And there does not appear to be significant change over the past 40 years. A longitudinal study published in 2017 calculated that annual productivity loss of medical services in the United States that is attributable to burnout may be equivalent to eliminating the graduating classes of seven medical schools ${ }^{3}$.

Medical students and residents have higher rates of burnout and depression than their professional peers who are pursuing nonmedical careers $^{4}$ and it isn't just a U.S. problem. Reports from around the world indicate that $27 \%$ to $75 \%$ of residents, regardless of their specialty experience burnout ${ }^{5}$.

To be precise, burnout is technically not a mental illness diagnosis. In fact, as Dr. Robert Wicks has pointed out, the very commitment to others and to the work of healing that fuels our enthusiasm, "is the same energy that causes us to ignore our own needs and inadvertently depletes our inner resources"6. There are levels of burnout which alert us to increased vulnerability to illness if symptoms remain unaddressed.

${ }^{1}$ Collier, R. "Addressing physician burnout at the systems level" CMAJ. 2018 Feb 12; 190(6): E174, doi: 10.1503/cmaj.109-5556

${ }^{2}$ Victor J. Dzau, M.D., Darrell G. Kirch, M.D., Thomas J. Nasca, M.D., Perspective: To Care Is Human - Collectively Confronting the Clinician-Burnout Crisis, January 25, 2018 N Engl J Med 2018; 378:312-314 DOI: 10.1056/NEJMp1715127

${ }^{3}$ Dyrbye LN, Shanafelt TD, Sinsky CA, et al. Burnout among health care professionals: a call to explore and address this under-recognized threat to safe, high-quality care. Washington, DC: National Academy of Medicine, July 5, 2017 (https://nam.edu/BurnoutAmong-Health-Care-Professionals).

${ }^{4}$ Ibid, p. 1

${ }^{5}$ Ishak WW, Lederer S, Mandili C, Nikravesh R, Seligman L, Vasa M, Ogunyemi D, Bernstein CA. Burnout during residency training: a literature review. J Grad Med Educ. 2009;1(2):236-42. Article Google

${ }^{6}$ Wicks, R. Bounce: living the Resilient life, New York: Oxford university Press, 2010, p.33.
It starts out as what has been called compassion fatigue that shows up physically, and if not addressed, in its chronic form may lead to addictive compensations, boundary violations, mental illness and/or suicide.

\section{Physician suicide}

The medical profession consistently hovers near the top of occupations with the highest risk of death by suicide. Some 3-400 U.S. physicians die by suicide every year ${ }^{7}$ or the loss of a doctor a day ${ }^{8}$. Suicide rates for male physicians are $70 \%$ higher and $250-400 \%$ higher for females when compared with the general population (including other professionals $)^{9}$. Suicide is usually associated with severe depression, anxiety and cognitive narrowing to myopic hopelessness regarding options. Researchers in the Interpersonal theory of suicide have pointed to "thwarted belongingness and perceived burdensomeness (and hopelessness about these states)"10 in conjunction with capability, as the most dangerous combination of variables predicting suicide potential.

Depression affects $39 \%$ of physicians at some point in their career, twice the rate of the general population ${ }^{11}$, and hopelessness is associated with severe depression. Unfortunately, physicians have traditionally been less likely than the general population to seek consultation, or if they do, hesitant to identify this. In a survey of 2,100 female physicians, one third reported receiving a formal mental health diagnosis since medical school, but only $6 \%$ disclosed their diagnoses to state licensing boards ${ }^{12}$. Most of those who self-identified also tried to manage their problem on their own, including writing their own prescriptions, rather than seeking professional support and consultation.

Dr. Christine Moutier reported in a psychological autopsy that physicians who died from suicide were 20-40 times more likely than

\footnotetext{
${ }^{7}$ Andrew LB. Physician suicide. Medscape. June 12, 2017, (https://emedicine.medscape. com/article/806779-overview).

${ }^{8}$ Shanafelt TD, Balch CM, Dyrbye L, Bechamps G, Russell T, Satele D, et al. Special report: suicidal ideation among American surgeons. Arch Surg. 2011 Jan. 146(1):54-62.

9 Tracy Hamptom, PhD, "Experts Address Risk of Physician Suicide" JAMA. 2005;294(10):1189-1191. doi:10.1001/jama.294.10.1189.

${ }^{10}$ Kimberly A. Van Orden, Tracy K. Witte, Kelly C. Cukrowicz, Scott Braithwaite, Edward A. Selby, and Thomass E. Joiner, Jr., The Interpersonal Theory of Suicide, Psychol Rev. 2010 Apr; 117(2): 575-600. doi: 10.1037/a0018697.

${ }^{11}$ Roger Collier, Physician suicide too often "brushed under the rug" Canadian Medical Association Journal . 2017 Oct 2; 189(39): E1240-E1241.doi: 10.1503/cmaj.1095498. ${ }^{12}$ Ibid.
}

${ }^{*}$ Correspondence to: Stephen Muse, PhD, Pastoral Institute, Inc., 2022 15th Ave., Columbus, 31901, Georgia, E-mail: Smuse@pilink.org

Received: January 11, 2018; Accepted: January 30, 2018; Published: February 02,2018 
the general population, to have taken benzodiazepines, barbiturates or antipsychotics prior to death. They were also three times more likely to have been experiencing problems at work ${ }^{13}$.

Suffering in isolation is a problem for physicians. Relatively few of those who suicided were being treated by psychiatrists. Evidence suggests that physicians do not adequately detect and treat depression in their patients ${ }^{14}$ let alone themselves. By focusing on the symptoms of the physical body apart from the full person of the patient, the larger context of depression which factors strongly in the etiology of the various physical symptoms is easily missed. Jean Claude-Larchet points to the vital need to think in personal context:

The body does not only express the person; to a certain extent it is the person. The person does not merely have a body, he or she is a body, even though the person as such infinitely transcends bodily limits. This is why everything that involves the body involves the person as a whole. By refusing to consider the spiritual dimension of human persons when we seek to alleviate their physical ailments, we do them immeasurable harm ${ }^{15}$.

As part of Moutier's research at a large University Medical program, an online anonymous interactive screening program was created and faculty physicians and medical students were able to complete questionnaires and engage in anonymous dialogues with counselors about their personal situation. This resulted in a $40 \%$ increase in medical students seeking help and 230 referrals of doctors for treatment. Since the program began 11 years ago, there has been only one death by suicide among the faculty physicians ${ }^{16}$ in contrast to 13 who suicided during the previous 15 years.

Forty years ago, in a special article in a 1977 issue of JAMA on physician suicide, the authors pointed to what they called the "psychological barrier" toward recognizing personal illness that is related to a certain personal ethos that mitigates against physicians seeking help.

Doctors tend to regard personal illness as weakness, a narcissistic injury which triggers defensive psychic regression and impairs realityappreciation, allowing the doctor to deny a suicidal danger that would be quickly detected in a patient. This denial is often supported by the doctor's fantasy that he or she is a miraculous healer, immune to disease ${ }^{17}$.

It was suggested that colleagues may see signs of mental suffering in the physician as "weakness", creating a climate of secrecy and shame over having something wrong with the one who is by vocation, called to offer healing to others.

\section{Uncomfortable with vulnerability}

Fifteen or so years ago a family resident consulted with me and told me "I need a place to cry." He said that the climate at the hospital was such that feelings were not tolerated in the physicians. Around that same time, I happened to make a visit to the hospital and was sitting at the table with some of the residents and the psychologist who worked with them. They had never met me and didn't know who I was. When the

${ }^{13}$ Ibid.
${ }^{14}$ Ibid.
${ }^{15}$ Larchet, Jean-Claude., The Theology of Illness. New York; St. Vladimir's Seminary
Press, 2002, p.13.
${ }^{16}$ Op Cit.
${ }^{17}$ JAMA 237:143-145, 1977)

psychologist got up to get something, one of them sprang up from his seat, and sat in his empty chair, wiggled his rear-end and said effusively in a mocking way, "Can't you just feel those touchy-feely vibrations?"

A 1998 JAMA article reported results from a national survey of medical residency programs in the U.S. and found a culture where shaming and emotional tension appears to be a frequent experience. $38 \%$ reported being slapped, pushed, kicked or hit during their training ${ }^{18}$. This sort of behavior emerges from overstressed systems and from relationships that lack vulnerability and mutuality, often justified rationally by the intensity and precision in medicine which is a frontline battle with death.

Some years ago, I was invited to California for a consultation with a team of Emergency Room docs and nurses in a large medical system. Their stress had accumulated to the point that the staff was constantly on edge. One of the docs was screaming and regularly dropping the $\mathrm{F}$ bomb with personnel and morale was deteriorating. A few hours into my presentation, this physician, who hailed from one of the top medical schools in the U.S. spoke up loudly with disdain and launched into an instructive rant as to why emergency medicine is dealing with life and death and he did not have time for incompetence or delay. His implied that his actions and intensity with incompetent or unresponsive staff were justified and it couldn't be otherwise. I responded by inviting him to consider if he felt justified in going home and being emotionally abusive to his wife because he was under stress. He subsequently entered into a coaching relationship to address what was causing him to lose his temper and behave as he did. His story is not unlike the description of authors of a study on physician suicide who observed that physicians, often possess compulsive personality traits, such as feeling an exaggerated sense of responsibility and perfectionism. While these characteristics promote thorough and conscientious care that is beneficial in medical practice, they may also lead physicians to feel vulnerable, overwhelmed, and manage stress poorly. Often, physicians are reluctant to take vacations, have trouble balancing work-family commitments, and frequently believe that they are "not doing enough"19.

Douglas Graham, MD with the Physician Support Program, British Columbia identified what he calls the "five soul killers" of physicians: isolation, fear, anger, exhaustion and shame. Physicians reporting suicidal ideation often lack personal supports ${ }^{20}$. Female physicians, psychiatrists and anesthesiologists are at an increased risk of suicide compared to other specialties ${ }^{21}$. Physicians who recently considered suicide were found to be "five times more likely to report personal problems, three times more likely to report financial problems, and roughly two times more likely to report health or work problems as compared with those not thinking about suicide ${ }^{22}$.

A physician made a monthly two-hour drive for a consultation on loss of vocational satisfaction in his group practice which had begun

\footnotetext{
${ }^{18}$ Daugherty SR, Baldwin DC, Rowley BD. Learning, satisfaction, and mistreatment during medical internship: a national survey of working conditions. JAMA. 1998; 279:1194-1199.

${ }^{19}$ Op. Cit.

${ }^{20}$ Elizabeth Brooks, Michael H. Gendel, Sarah R. Early \& DorisC. Gundersen (2017) When Doctors Struggle: Current Stressors and Evaluation Recommendations for Physicians Contemplating Suicide, Archives of Suicide Research, DOI:10.1080/13811118.2017.1372827.

${ }^{21}$ Hawton, K., Clements, A., Sakarovitch, C., Simkin, S., \& Deeks, J. J. (2001). Suicide in doctors: A study of risk according to gender, seniority and specialty in medical practitioners in England and Wales, 1979-1995. Journal of Epidemiology and Community Health, 55(5), 296-300; . Torre, D., Wang, N., Meoni, L. A., Young, J. H., \& Klag, M. J. (2005). Suicide compared to other causes of mortality in physicians. Suicide \& Life-Threatening Behavior, $35,146-153$

${ }^{22}$ Op. Cit.
} 
to be money-focused in the face of increased time management and production numbers. He was highly analytical but yearning for something deeper that he was missing. I discovered that he had come from an alcoholic family where he had learned to survive through achievement and by learning to be unaware of his own emotions, as he tried to avoid shame and protect his family secret. In our conversation he experienced puzzlement when he had a strong physical affective reaction as we talked, that he couldn't account for rationally. This opened a door for him that began to change his marriage relationship and led him to address his vocational dissatisfaction by going to each doc in his group practice and asking where he stood on values and the way of practicing medicine. When he discovered he was in the minority in his views, he made the decision to leave the group practice and begin his own where he found another couple physicians who shared his values about patient care. He was willing to sacrifice considerable assets in order to do so. But he was very happy with the changes. Whatever vulnerabilities there are in terms of the physician's personality and typical coping patterns, these are further potentiated by circumstances affecting the practice of medicine which include increasing regulation by federal and health management policies; restrictive and cumbersome electronic health records, lowered pay, increasing work loads with less personal control, and lowered job satisfaction as a result of a combination of these factors. There is a Yiddish proverb that captures the direction we have been moving in this regard: "Sleep faster, we need your pillow."

\section{Sleep deprivation, exhaustion and medical errors}

There is no question that physicians are under constant pressure to avoid harm coming to patients. Statistics on deaths from medical error are difficult to find in published literature. Thirty-year-old data from the Institute of Medicine's 1999 report put the figure at 98,000 deaths annually ${ }^{23}$. A more recent conservative estimate is 200-300,000 deaths annually, or about 700 people a day, making medical error the third leading cause of death in the U.S. Mayo Clinic physician Steve Swenson adds to that number, "And most of those have a second victim: the nurses, doctors, social workers, managers, pharmacists involved in their care"24.

A 2017 survey of 3,171 physicians points out how medical culture tends to encourage perfectionism, isolation and individual blame when it comes to medical errors and physicians suffer an inordinate amount of mental and emotional distress in the wake of mistakes ${ }^{25}$. Two-thirds of physicians in the study reported increased anxiety about making future errors. In addition, just under half reported a loss of confidence, sleeping difficulties, and reduced job satisfaction. More than $80 \%$ of these physicians expressed an interest in counseling after a serious error, but unfortunately, only $10 \%$ agreed that their health care organizations adequately supported them in coping with error-related emotional distress.

${ }^{23}$ Jacob, A. "Medical Errors: The Third Leading Cause of Death in the United States", May 17, 2017, http://www.mdmag.com/conference-coverage/aapa-2017/medical-errorsthe-third-leading-cause-of-death-in-the-united-states.

${ }^{24}$ Tait Shanafelt, MD, Christine A. Sinsky, MD, FACP \& Stephen Swensen, MD, MMM, FACR

"Preventable Deaths in American Hospitals" NEJM Catalyst, Mayo Clinic, American Medical Association, Jan, 23, 2017. https://catalyst.nejm.org/medical-errors-preventabledeaths/.

${ }^{25}$ Jennifer J.Robertson, MD, MSED, Brit Long, MD, "Suffering in Silence: Medical Error and its Impact on Health Care Providers," Journal of Emergency Medicine, https://doi. org/10.1016/j.jemermed.2017.12.001
The physician is often sacrificing his or her well-being in order to fulfill the administrative and patient requirements while neglecting personal health, family well-being and spiritual vitality. One area this affects is getting sufficient rest. Sleep deprivation is a serious impediment to cognitive and manual dexterity processes.

Even moderate amount of time without sleep (17-19 hours) is associated with performance decreases equivalent to .05 blood level of alcohol and 24 hours is equivalent to $.1 \%$ blood alcohol ${ }^{26}$. Sleep deprivation impairs judgment and increases vulnerability to addictive compensations by decreasing satisfactions that are part of normal sobriety. It can also disrupt replenishment of neurotransmitters in the brain which can effect mood.

U.S. Army research revealed deterioration in performing artillery exercises, from $98 \%$ efficiency at 7 hrs. sleep, to $50 \%$ after only two weeks of 6 hours sleep and $85 \%$ deterioration with two weeks of 4 hours of sleep ${ }^{27}$. Both cognitive capacity and manual dexterity decrease. Handeye coordination is poor and symptoms of tiredness, loss of joy (similar to symptoms of depression) increase. Sleep debt decreases serotonin and other neurotransmitters in the brain which are replenished in delta wave deep sleep. This is also significant because depression in an otherwise healthy 45 -year-old male increases the chance of heart attack by $50-100 \%{ }^{28}$.

\section{Systemic considerations}

In January 2017, the National Academy of Medicine, in collaboration with the Association of American Medical Colleges (AAMC) and the Accreditation Council for Graduate Medical Education (ACGME), launched a national Action Collaborative on Clinician Well-Being and Resilience ${ }^{29}$ with four central goals:

1) to increase the visibility of clinician stress and burnout,

2) to improve health care organizations' understanding of challenges to clinician well-being,

3) to identify evidence-based solutions,

4) to monitor the effectiveness of implementing these solutions.

The collaborative suggested that "We already know that burnout is driven largely by external factors, rather than by personal characteristics" which include:

- work-process inefficiencies (such as cumbersome IT systems),

- excessive work hours and workloads

- work-home conflicts

- problems with the organizational culture (such as team dysfunction and management styles that neglect clinician input),

${ }^{26}$ A M Williamson, Anne-Marie Feyer, "Moderate sleep deprivation produces impairments in cognitive and motor performance equivalent to legally prescribed levels of alcohol intoxication" Occup Environ Med 2000;57:649-655.

${ }^{27}$ Banderet, L.E., Stokes, J.W., Francesconi, R., Kowal, D.M., Naitoh, P. (1981) Artillery teams in simulated sustained combat: Performance and other measures. pp. 581-604 in DHHS (Department of Health and Human Services) NIOSH (National Institute for Occupational Safety and Health) Report 81-127: The Twenty-Four Hour Workday: Proceedings of a Symposium on Variations in Work-Sleep Schedules, L.C. Johnson, D.I Tepas, W.P. Colquhon \& M.J. Colligan, eds. Washington, DC: Government Printing Office.

${ }^{28}$ Marano, H.E., “Depression: Beyond Serotonin” Psychology Today, Mar/April, 1999, p. 72.

${ }^{29}$ National Academy of Medicine. Action Collaborative on Clinician Well-Being and Resilience. 2017 (https://nam.edu/initiatives/clinician-resilience-and-well-being). 
- perceived loss of control and meaning at work.

and decided to focus on promoting solutions and progress at organizational, systems, and cultural levels" ${ }^{\prime 30}$. I was interested in the comments from physicians who read the article which identified key areas of need as well as frustration. One wrote,

Physicians must empower themselves to draw personal and professional boundaries around the need for restorative sleep cycles, physical activity and recreation and proven interventions in reduction of stress and occupational strain including meditation, yoga, gardening and walking in green environments.

Another responded,

One of the largest causes not mentioned is the stress on doctors arising from their guilt, anger, and disillusion---that builds up when they cannot keep perfectly to their values. I have heard that the doctors' lounges, libraries, and cafeterias have been closed down in many institutions----the places where doctors expressed their feelings and got their feet back on the ground. Michael Balint started discussion groups for doctors in England in 1949 and the American Balint Association struggles manfully to carry on, but many clinics and doctors say they have no time for that."

The one that stuck out most for me, wrote,

Drs. Wright and Katz's Perspective may be extremely telling by the order in which they discuss approaches to "managing" burnout. Before anything else, they apparently felt the need to reassure "there's a business case for addressing (the issue)."

And he then quotes the offending passage which reads:

The "External Factors and Work Flow" workgroup is exploring approaches to optimal team-based care and documentation in the rapidly evolving digital health environment. And the "Messaging and Communications" workgroup is identifying key stakeholders and developing targeted messaging to disseminate available evidence and knowledge and thus inspire action. A key deliverable for the collaborative is an online "knowledge hub"..." OH MY GOD This reads like a parody of pompous bureaucratic-speak. This will help the physicians doing the daily work how, exactly? Besides earnestly discovering the need for further study, I mean?

Recently, the American College of Physicians suggested that as much as 80 percent of the causes of physician dissatisfaction and lack of well-being are systems issues" 31 and in response are promoting a "patients before paperwork" approach, seeking to find ways to lessen administrative burdens imposed by the regulatory agencies and insurance requirements. "In multiple recent studies, electronic health records have been shown to decrease professional satisfaction, increase burnout, and the likelihood that a physician will reduce or leave clinical practice" ${ }^{32}$ as a result of a combination of factors including loss of income, increased work load, lack of control over the work flow and decreased vocational satisfaction.

Since it is highly unlikely in the near future that there will be a lessening of EHR demands, and because circumstantial and system

${ }^{30}$ Op. Cit. Zau, Kirch \& Nasca, 2017.

${ }^{31}$ Collier, R. "Addressing physician burnout at the systems level" CMAJ. 2018 Feb 12; 190(6): E174, doi: 10.1503/cmaj.109-5556.

${ }^{32}$ Ehrenfeld, Jesse M.; Wanderer, Jonathan P.,Technology as friend or foe? Do electronic health records increase burnout? Current Opinion in Anesthesiology: February 22, 2018

- Volume Publish Ahead of Print - Issue - p, doi: 10.1097/ACO.0000000000000588. factors are experienced differently according to inner resources, in order to implement a "patient before paperwork" approach, we cannot ignore the importance of the person of the physician and the inner life of the mind and heart and relationality that have been the emphasis of all the ancient spiritual traditions.

\section{Attention restoration}

A 2017 Physician focus Group on 'How to improve the well-being of General Practitioners' came up with a simple suggestion that was doable and met multiple necessary needs. In light of the fact that lunch breaks were not viewed as a realistic option that could be implemented, one compulsory daily coffee break was viewed $\mathrm{as}^{33}$.

fulfilling psychological needs by having a mental break from 'being the doctor,' meeting physical needs by having opportunity to have something to drink, eat some food, and perhaps get some fresh air, take a toilet break and meet social needs through interacting with colleagues.

As simple as this may seem, it is also at the heart of recent research on the need for five minutes of relaxed unfocused attention for every thirty minutes which is focused. (Anybody remember what God did on the seventh day according to Genesis, after 6 days of focused creating?) Every $7^{\text {th }}$ day, every $7^{\text {th }}$ hour, every $7^{\text {th }}$ minute we need to STOP and encounter silence and stillness.

If you have never read the Tao Teh Ching it is a wonderful short meditation on the need to appreciate the immensity of the Created order and the power of the unnoticed. For example, "We shape clay into a pot, but it is the emptiness inside the pot that holds whatever we want." Or "Sharpen a blade too much and you will dull it." There is a balance to life that cannot be ignored without creating disharmonies.

Attention that is not constantly focused on work but allowed to be attracted to beauty, the natural environment and involved in play, is something that in the Psychology of Restorative Environments is called, "attention restoration." There are basically two types of attention - one is focused and concentrated willfully and another is freely attracted, relaxed and interested. Drawing on this notion, several qualities characterize environments that facilitate attention restoration that are pertinent to our discussion.

1) a sense of being away from work and routine that requires sustained directed attention. This may be psychologically and/or geographically.

2) being engaged in effortless exploration of interesting environmental processes.

3) Experiencing fascination of effortless attracted attention promotes rest for the inhibitory mechanisms involved in making directed attention possible.

(This can be a hard fascination gripping the senses (like watching an action movie) or soft aesthetic attraction (like being beside a waterfall or relaxing in a coffee break) $)^{34}$

One of the things I do that is restorative, is to take time for silence and prayer daily, spend time in nature regularly, and make an annual

${ }^{33}$ Louise H Hall, Judith Johnson, Jane Heyhoe, Ian Wattc, Kevin Andersond, and Daryl B O'Connor, Strategies to improve general practitioner well-being: findings from a focus group study, Family Practice, 2017, 1-6 doi:10.1093/fampra/cmx130.

${ }^{34}$ Staats, H. "Restorative Environments," The Oxford Handbook of Environmental and Conservation Psychology, Sep. 2012, Online Publication Date: Nov 2012 DOI: 10.1093/ oxfordhb/9780199733026.013.0024. 
short trip to a monastery, often as a preamble to a vacation. One 2005 study showed that a stay in a monastery was partly motivated by restorative needs, and that visitors felt rested, clearheaded, competent, and alert at the end of their stay ${ }^{35}$.

Vacations and short Sabbaticals can be useful in this regard, but more importantly, small moments need to be built into the day as part of a vocational path of meaning. In the week-end presentation for the stressed-out group practice E.R. docs and nurses I referred to earlier, what amazed me, is that with the data before them they met and within one week, made the decision to each set aside $10 \%$ of their profits into a fund that could be used to help make 3-month sabbaticals for each of them. Anyone who did not take theirs, forfeited what they put in. This practical, reasoned approach grew out of addressing the data and deciding on a course of action that could change things. In this case it involved therapy and coaching for several of the staff; one person leaving medicine and the others banding together to make organizational changes that would support their well-being.

In terms of work environment, a simple experiment showed that participants in offices with plants improved their performance on an attention-demanding task over trials while participants in the same office without plants did not ${ }^{36} \mathrm{~A}$ number of hospitals have begun incorporating the refreshment of natural scents in the waiting rooms with tangible results in a number of areas.

\section{Empathy and the person of the physician}

Empathy is another critical area of importance. I remember Jay Haley, one of the outspoken pioneers of family systems and cybernetic theory, speaking to the physicians at York Hospital in Pennsylvania back in the late eighties. He was talking about the rigor of medical school and its high demands and suggested that the requirements for academic focus and the willingness to sacrifice personal need so that everything serves the demands of medicine, had gradually been weeding out people inclined toward empathy!

Studies have subsequently confirmed the value of empathy in reducing physician stress and enhancing the quality of the healing partnership which involves emotional skills and perception. One of the ways medical schools have attempted to change the culture is by accepting a more varied student body than only valedictorians, and by introducing medical humanities into the curriculum. Among medical students ( $n=912)$, "regression analyses revealed that exposure to the humanities [literature, music, art] was significantly correlated with a variety of positive personal qualities, including empathy ${ }^{37}$. Moreover, each of the areas of significance identified, e.g., tolerance for ambiguity; wisdom; emotional appraisal; self-efficacy; and spatial skills, were inversely correlated with components of burnout. Most significantly, exposure to humanities turned out to be a predictor of significant

${ }^{35}$ Ouelette, P., Kaplan, R., \& Kaplan, S. (2005). The monastery as a restorative environment. Journal of Environmental Psychology, 25, 175-188.

${ }^{36}$ Raanaas, R. K., Evensen, K. H., Rich, D., Sjostrom, G., \& Patil, G. (2011). Benefits of indoor plants in an office setting. Journal of Environmental Psychology, 31, 99-105.

${ }^{37}$ Salvatore Mangione, MD, Chayan Chakraborti, MD, FACP, Giuseppe Staltari, MD,

Rebecca Harrison, MD FACP, Allan R. Tunkel, MD PhD, Kevin T. Liou, MD, Elizabeth Cerceo, MD,Megan Voeller, MA, Wendy L. Bedwell, PhD, Keaton Fletcher, BS, and Marc J. Kahn, MD, MBA,FACP11 "Medical Students' Exposure to the Humanities Correlates with Positive Personal Qualities and Reduced Burnout: A MultiInstitutional U.S. Survey,” , J Gen Intern Med, 2018, DOI: 10.1007/s11606-017-4275-8 decreases in physical fatigue; emotional exhaustion; and cognitive weariness ${ }^{38}$.

Dr. Damon Dagnon, in an article in the Canadian Journal of Medical Education, reflecting on the person of the physician, identified three key "principles" which I believe are essential to the discussion of burnout and physician resilience.

\section{1) "The first principle of the "physician as person" framework is that encounters with patients occur primarily between two people}

\section{Drawing from his own experiences, he writes,}

My defining and life-changing moment came when my threeyear-old son died from cancer. Today, not one shift goes by that my tragic life experience hasn't affected at least one patient encounter on a daily basis. I am a different doctor having experienced the extreme challenges of living in a hospital with a critically ill child, and, following his death, continuing to struggle with the hole that is forever in my heart. Listening to patients' personal stories of their illness, I often find myself sitting on the side of their ER bed trying to make a more human connection with the person (the patient) beside me. ${ }^{39}$

Above all, the healing partnership is distinguished from a mere technical procedure and sustained by its personal quality. The difference between authentic dialogue with the patient and the monologue of technical doing is that monologue leaves the entire burden of success irrationally on the physician and decreases the intangible but real contributions of relationality. A man with terminal cancer attempted suicide while in the hospital by cutting the arteries under his arms. Psychiatrists were brought in to talk with him and each was frustrated by what they termed his "resistance." Finally, a young psychiatric resident met with him as a person rather than objectifying him as a 'patient' and found out he was a philosophy professor. He asked him if he could teach him what he was learning about dying. The man now had a reason to live and was no longer suicidal. The willingness to be vulnerable and have an authentic dialogue with his patient proved healing for both physician and the patient who entered into a mutually beneficial reciprocity.

A second principle of the physician as person framework, Dagnon describes is related to this reciprocity. He defines this as

2) The power of being vulnerable, of opening up and letting patients and colleagues see your imperfect humanity apologizing, having tears, and sharing moments of pain cannot be overstated and further reinforces the physician as person.

\section{He writes,}

It is no coincidence that humanity and humility share the same Latin roots. Yes, it is our duty as physicians to care for our patients and focus on their needs, but somehow in that commitment, we run

${ }^{38}$ Salvatore Mangione, MD, Chayan Chakraborti, MD, FACP, Giuseppe Staltari, MD, Rebecca Harrison, MD FACP, Allan R. Tunkel, MD PhD, Kevin T. Liou, MD, Elizabeth Cerceo, MD, Megan Voeller, MA, Wendy L. Bedwell, PhD, Keaton Fletcher, BS, and Marc J. Kahn, MD, MBA, FACP, Medical Students' Exposure to the Humanities Correlates with Positive Personal Qualities and Reduced Burnout: A Multi-Institutional U.S. Survey. J Gen Intern Med. 2018 Jan 29. doi: 10.1007/s11606-017-4275-8. [Epub ahead of print].

${ }^{39}$ J. Damon Dagnon, "Commentary: The physician as person framework: How human nature impacts empathy, depression, burnout, and the practice of medicine," Can Med Educ J. 2017 Dec; 8(4): e97-e98. 
the risk of losing out on being able to communicate our uncertainties, disappointments, failures, and challenges. As a bereaved parent, looking back at my experiences in the hospital years ago, the most powerful connections I made with certain doctors was in large part due to their ability to be vulnerable with my wife and me. Towards the end of my son's life, they did not have any answers and made some mistakes, and because they were vulnerable with us, we shared the burden of the difficulties together. ${ }^{40}$

Failing this, the physician who does not recognize God as the healer and death as the revealer of humility, ends up in a struggle to deny death by feeling as if everything is up to him or her, opening the door to burnout.

Dr. Atul Gawande in his N.Y. Times bestseller Being Mortal: Medicine and What Matters in the End, describes how recurring dreams captured this unconscious fear in him.

"I am in a profession that has succeeded because of its ability to fix. If your problem is fixable, we know just what to do. But if it's not? The fact that we have had no adequate answers to this question is troubling and has caused callousness, inhumanity, and extraordinary suffering.... Dying and death confront every new doctor and nurse. The first times, some cry. Some shut down. Some hardly notice. When I saw my first death, I was too guarded to cry. But I dream about them. I had recurring nightmares in which I'd find my patients' corpses in my house-in my own bed. "How did he get here"? I'd wonder in panic. I knew I would be in huge trouble, maybe criminal trouble, if I didn't get the body back to the hospital without getting caught. I'd try to lift it into the back of my car, but it would be too heavy. Or I'd get it in, only to find blood seeping out like black oil until it overflowed the trunk. Or I'd actually get the corpse to the hospital and onto a gurney, and I'd push it down hall after hall, trying and failing to find the room where the person used to be. "Hey!" someone would shout and start chasing me. I'd wake up next to my wife in the dark, clammy and tachycardic."

I will forever be grateful to my friend and colleague George Zubowicz, MD, who afforded me the gift of friendship and witnessing the power of watchfulness, repentance and love as he shared his experience of what I call humbiliation ${ }^{41}$ under the direction of the cancer who was his teacher in his final days.

Respected and beloved, George had served many years as medical director of the Bradley Center psychiatric hospital and later as a psychiatrist on the out-patient staff of the Pastoral Institute where we became friends. We would stop by each other's office occasionally for conversations about psychotherapy, good books and the mysteries of life. He and Charlotte and Claudia and I would have dinner to share some of the cherry Vodka he taught me how to make. He was an Orthodox Christian with a true Russian soul. At his request, I offered a eulogy for his beloved wife Charlotte's memorial as well as for his own a year or so later.

George had a distinguished career as Menninger-trained psychiatrist who valued the integration of spiritual, medical and psychological care and was one of the founding fathers of the Pastoral Institute.

Outwardly stern and matter of fact, this towering bear of a man was the one person the staff would always go to when an unstable patient

$$
{ }^{40} \text { Ibid. }
$$

${ }^{41}$ I use the word "humbiliation" in place of humiliation to distinguish the humbling that comes from willingly bearing one's unmasking in repentance and love, for the sake of Truth, in contrast to the shaming humiliation that results from seeking to avoid it in a futile attempt at vainglorious self-preservation. went AWOL against medical advice, leaving the building in reactivity. George would lumber out the door quietly and slowly, without speaking, and in a few minutes, as our receptionist Gerry Taylor loved to say when she recounted the story, "Here would come the person following behind Dr. Z. as docile and obedient as a lamb."

I knew some of his remarkable life history from our conversations together - how he had traded most of his possessions as a boy to buy books to satisfy his voracious intellectual appetite after he had devoured a Dostoevsky novel with intense interest. He was equally on fire for athletic prowess as well. He told me that on one occasion when he was training for the Olympics, something was revealed to him in an unusual way. He had been pushing himself to the limit physically in his training when he heard a voice audible within him that said quietly and with an authority that did not coerce or force, "You can continue, but you will die." He stopped.

Ever the scientist, explorer and closet mystic, he was still discovering things about the limits of human power and the importance of vulnerability and compassion in his life by undergoing self-examination up to his last breath. Like St. Augustine, he had learned the value of 'becoming a question for myself.' Under the onslaught of cancer, which relentlessly sapped away the last of his physical strength daily, his mind remained vigilant for every lesson he could learn.

Having discovered early in life that his body would be obedient to his will to the point of sacrificing itself entirely, what did it now mean that his will remained strong while his body refused to obey it? He was powerless to cure himself or to prolong his life.

In his last days, on my visits with him we would talk together about what he was learning in the undiscovered country along a road less travelled. This man, who had been still competing and winning Senior Olympic swim meets in Europe in his eighties, who as they say "had never been sick a day in his life," described what he was now experiencing as his body grew weaker and weaker.

At one point, I said to him, "It seems to me that your biggest surprise in all this is that your 'I,' which does not feel weak at all, can exist in this body which cannot even find the strength to make it to the bathroom."

He responded with excitement and vigor from his frail body, in his thick Russian accent and rational manner, "That is correct. You understand me exactly!" Then he told me, "You know I had a contract for many years with the nursing home. I would visit and ask each person, 'How are you doing?' and the person would say, 'Fine.' And I would write this in my book and go on to the next one. You hardly have time to do more than that, but now that I have had this weakness, I realize that I did not really ask them how they were. This is because they were sick and helpless and I had never felt this in my life." In a different voice, softer, but with humility, compassion and a kind of wonder, he continued, "Now I understand what this means. Can you imagine that?"

Then in a clear impassioned, sober voice, with a touch of wistful remorse he added, "For fifty years I have been a psychiatrist, and I did not really know how to ask people how they are in a way that really means it." The importance of vulnerability and empathy in resilience and sustaining the healing partnership cannot be overemphasized.

Along with humility, vulnerability and person-to-person relationship, the third principle of Dagnon's framework is 


\section{3) That the physician's personal and professional life should avoid being compartmentalized.}

He writes,

As physicians, it is unhealthy to be a different person in the professional context than who we are in the personal context. It is also not natural or wholesome, and yet it can be frequently found as an insidious and powerful part of physician culture. Listening to patients, taking a history, performing a physical exam, embarking on a management plan, and communicating the essential parts of a clinical encounter must not be a mechanistic or strictly professional interaction that is separated from ourselves as people. To do these tasks effectively, a humanistic approach that makes a connection with the person (the patient) in front of you is what's needed, and in my opinion, highly valuable $e^{42}$

This brings me to my final reflection on physician resiliency and prevention of burnout, which has to do with recognizing the relationship between the type of work one is involved in and the effects of what I have called "iatrogenic aromoring"

\section{Iatrogenic armoring}

There is a children's story called the Rusty Knight about the problems encountered when a noble knight is unable to remove his armor after battle. It is a parable of sorts, that serves to illumine the dangers of becoming trapped in one's armor. Like the knight, physician may find it difficult to move between the demands of the battlefield of health-care delivery and the very different, but equally vital demands of marriage, family and personal life in an integrated way. What protects individuals in one arena can be dangerous to life in another. Loss of a sense of vocation, relationality, meaning and purpose lie at the heart of burnout and the symptoms of vicarious trauma which can result from the accumulation of the protective avoidance of intense engagement with suffering, death and personal loss that are part of the physician's daily life and work.

Dr. Richard Gunderman points out how this is often overlooked in discussions of burnout among physicians.

"[B] urnout at its deepest level is not the result of some train wreck of examinations, long call shifts, or poor clinical evaluations. It is the sum total of hundreds and thousands of tiny betrayals of purpose, each one so minute that it hardly attracts notice. [Physicians] find themselves expressing amazement and disgust at how far they've veered from their primary purpose." ${ }^{44}$

These considerations point us to the critical importance of reciprocity in the healing partnership. It is not a one-way technical exchange, as the language of "providers and consumers" and emphasis on "best practices" would lead us to believe. The physician is first of all a personal co-sufferer and co-pilgrim with the patient in the human condition.

Someone who read one of my books ${ }^{45}$ recently gave me the obituary of the orthopedic physician I had mentioned in it, who had treated

\footnotetext{
${ }^{42}$ Ibid.

${ }^{43}$ Muse, S., Brende, J. "Physician, Heal Thyself!," HumaneHealthCare.com (formerly Journal of Humane Health Care), 2003, Vol 3(2) pp 1-20.

${ }^{44}$ Richard Gunderman, The Atlantic, Feb 21, 2014. HTTPS://WWW.THEATLANTIC. COM/HEALTH/ARCHIVE/2014/02/FOR-THE-YOUNG-DOCTOR-ABOUT-TOBURN-OUT/284005/.
}

${ }^{45}$ Muse, S. When Hearts Become Flame, New Canaan: St. Tikhon's Monastery Press, 2016. my mother during the entire time of my life from my early childhood through college. I watched my mother go in and out of the hospital for countless operations as she was ravaged by an auto-immune fire that finally attacked even her organs. At her funeral, Dr. Golder, came over to me and said "Your mother was the sickest person we ever treated at Duke Medical Center and it broke my heart that nothing we ever did helped her." This was from a man whose gentleness, sobriety and generosity had moved me even as a boy.

Dr. Leonard Goldner was the James B. Duke Professor and later, Chairman Emeritus of the Duke University Medical Center Orthopedics Department and an internationally acclaimed surgeon and author. In a 2001 article from the American Journal of Orthopedics, he reflected on the humanity of physicians and the vital importance of the relationship of care established with each patient as well as balance in the physician's life, which are hallmarks of resilience. He titled his reflections, "Attitude" and counseled physicians to, "Look in the mirror each morning and ask: "What should I do to enjoy this day? You owe your patients full-time care, but you also owe time to yourself and your family ${ }^{46}$. He quotes Nicholas Murray Butler, a former President of Columbia University who defines the educated person as one who "can do what he ought to do when he ought to do it, whether he wants to do it or not." and goes on to say

You must be able to analyze your feelings, your fatigue symptoms, and your physical and emotional capabilities. You must also recognize that, occasionally, your patient's problems are not solvable. [But what a patient can expect] is to receive your personal interest, undivided attention, a courteous, positive response to questions, a 'hands-on' examination, and an explanation of a tentative diagnosis ${ }^{47}$.

He points to the whole person of the physician and reminds his colleagues that empathic relationship is central to physician resilience and the healing partnership and it must be evident in even the smallest of gestures.

What the patient hears accounts for only $10 \%$ of the total information imparted, and the overall attitude, body movements, eye contact, method of greeting the patient, and way of talking while either standing or sitting account for $50 \%$ of the physician impression on the patient ${ }^{48}$.

Finally, he asks physicians to always remember when communication with a patient becomes difficult, "the patient is sick, not you."

Among the attributes in his obituary, published in 2006 in the Journal of Bone and Joint Surgery, it was noted that

Dr. Goldner was a complete physician. He taught how to evaluate patients through talking to them and also listening to them, learning not only about their complaints and mechanism of injury but also about their work, family, social behavior and desires and expectations. He never looked at radiographs or other images until he had obtained a complete history and performed a very thorough examination. By his practice, Dr. Goldner proved that a warm and compassionate engagement with the patient was $90 \%$ responsible for gaining the respect of the patient even if a precise diagnosis was not made. $\mathrm{He}$ demonstrated that appropriate facial expressions, body movement, a calm voice, and an overall friendly attitude were the main ingredients

\footnotetext{
46 J. Leonard Goldner, M.D. Guest Editorial "Attitude" The American Journal of Orthopedics, Jan. 2001, pp. 185-190.

${ }^{47}$ Ibid.

${ }^{48}$ Ibid
} 
of a good and lasting doctor-patient relationship. He never appeared hurried or rushed and his colleagues never heard him speak in an angry or harsh voice to a patient, nurse, attendant or to anyone around him.

That's how I remember him as well. When he found out that my grandfather had sold his house to pay my mother's medical bills, he refused to charge her for his professional services for the rest of her life - an extraordinary gesture that continued for some fifteen years. His wife visited my mother regularly in the nursing home until the end of her life and their caring relationship, more than any physical medicine, were part of what sustained her hope in the face of a relentless series of defeats.

\section{The power to change is within us}

Current circumstances make the practice of medicine challenging, for sure, but the power to change our lives does not rest in the conditions outside of us, but with the life that is available to each of us without cost, free for the receiving, if only we will regularly go deep enough into the stillness of our own hearts and show up fully in the presence of authentic embodied relationships with the people and world around us.
The British philosopher Ludwig Wittgenstein made a profoundly helpful epistemological distinction when he wrote, "It is not how things are in the world that is mystical but that it exists." ${ }^{39}$ Gratefulness for the gift and recognition of the mystery of even the simplest of interactions we typically take for granted, is necessary in order to be nourished and refreshed in our lives on a daily basis. Gratefulness is the life-restorative movement in the heart that oxygenates the work of doing with the refreshment of being that arises from Sabbath rest.

Being rooted in person-to-person presence and authenticity with gratefulness and humility before the gift of life, constitutes the foundation for a truly realistic respect for the thatness of patient and physician as persons. What Drs. Dagnon, Zubowicz, Gawande, and Goldner have articulated and embodied-the virtues of humility, vulnerability, compassion and personal relationality-are I believe, the critical ingredients in physician resilience and the primary means for sustaining the healing partnership and fulfilling the vocation of the good physician.

49 Wittgenstein, L. Tractatus Logico Philosophicus, United States Seven Treasures Publications, 2010, (6.44).

Copyright: $\odot 2018$ Muse S. This is an open-access article distributed under the terms of the Creative Commons Attribution License, which permits unrestricted use, distribution, and reproduction in any medium, provided the original author and source are credited. 